\title{
EPISTEMOLOGIA EM EXTENSÃO RURAL E O TEMPO DA EXTENSÃO TOTAL
}

\author{
RURAL EXTENSION EPISTEMOLOGY AND THE TIME OF \\ TOTAL EXTENSION
}

\author{
Silvio Calgaro Neto \\ Universidade Federal de Santa Maria - Santa Maria - RS - Brasil \\ Renato Santos de Souza \\ Universidade Federal de Santa Maria - Santa Maria - RS - Brasil
}

\begin{abstract}
Resumo: Este artigo dedica-se a explorar e concertar o campo de conhecimentos diretamente relacionado à extensão rural. De modo geral, é utilizada uma estratégia teórica que concentra-se em apresentar três perspectivas complementares. Na primeira, realiza-se uma breve arqueologia em extensão rural, identificando suas marcantes contextualizações históricas. Na segunda, preza-se pela interpretação de alguns modelos teóricos extensionistas através da plataforma epistemológica moderna. E a terceira perspectiva busca apresentar uma proposta metodológica que contemple estas características epistêmicas, relacionando-a com as conjunturas contemporâneas observadas no âmbito da construção de conhecimentos e transferência de tecnologias para o desenvolvimento rural.

Palavras-chave: Instituições totais. Universidade. Educação tecnológica.
\end{abstract}

\begin{abstract}
This article is dedicated to explore the field of knowledge related to rural extension. In general, a three complementary perspective is used as theoretical strategy to present this epistemological study. The first perspective, seeks to accomplish a brief archeology of rural extension, identifying the remarkable historical passages. At the second, we look to some theoretical models through the modern epistemological platform. Finally, the third perspective, aims to present a methodological proposal that contemplate this epistemic characteristics, relating with the contemporary transformations observed in the knowledge construction and technological transference for a rural development.

Keywords: Total institutions. University. Technological education.
\end{abstract}

\section{Introdução}

"Um fenômeno pode estar entulhado. Isto significa: antes tinha sido descoberto mas, depois, voltou a encobrir-se" (HEIDEGGER, 1998, p.67).

Tratar sobre epistemologia em extensão rural, à primeira impressão, parece ser um pouco ambicioso. No entanto, a história contam que há muito tempo produzem-se comentários, pelos interessados no tema, que indicam a necessidade de se incrementar esse campo de estudo. Observa-se. nas práticas dos intelectuais dedicados formalmente à extensão rural, a relação com uma ampla gama de conhecimentos que, por sua vez, interagem com os mais diversos campos disciplinares e interdisciplinares. Quere-se saber, então, se há um campo de conhecimentos que poder-se-ia apontar como pertencente à episteme da extensão rural? O fenômeno a ser des-coberto busca evidenciar, portanto, a episteme da extensão rural ou episteme extensionista. Cabe destacar, enfaticamente, que parte-se do pressuposto de que uma perspectiva epistemológica deve ser entendida apenas como um complemento interativo com as possíveis perspectivas 
que possa, cada pessoa, lançar-se.

A proposta apresentada neste documento reconhece a enorme dimensão que pode assumir o exercício de teorização sobre o fenômeno em questão, entretanto, também identifica a necessidade de orientar-se ao mesmo, buscando, assim, elaborar caminhos para futuras complementações, críticas e renovações. 0 percurso assumido para a elaboração deste trabalho faz com que o mesmo recaia no âmbito das generalidades. Ainda assim, parece interessante destacar as observações genéricas reconhecidamente relacionadas ao campo teórico da extensão rural e que conformam, de modo geral, o "pano de fundo" para as infinitas derivações e replicações que podem ser construídas por meio dos diálogos intelectuais extensionistas. Nesse caso, entende-se aqui que a tentativa de descoberta da episteme extensionista exige, entre tantas possibilidades, ao menos, a elaboração de dois estudos particulares:

- Uma arqueologia da extensão rural;

- Uma epistemogeografia em extensão rural.

A elucidação do tema em questão, desse modo, perpassa inicialmente por uma breve (re)construção histórica. Ao levantar a hipótese de que há uma episteme extensionista, entende-se que se faz necessário resgatar um pouco da odisseia secular da extensão rural, explicitando alguns de seus momentos mais marcantes e que, segundo algumas referências, representam, atualmente, os "fósseis" da extensão rural. O objetivo, com isso, da segunda seção deste artigo é apresentar os eventos históricos que, bibliograficamente, são reconhecidos como relacionados à extensão rural, ou seja, busca-se apontar para os "lugares" da extensão rural na história.

Na terceira seção, buscar-se-á encontrar os "lugares" da extensão rural na epistemologia moderna. Quer dizer, utilizando uma metáfora territorial, elaborarse-á algumas proposições que visam a posicionar a episteme da extensão rural no que se chama de plataforma epistemológica moderna, quer dizer, um território epistemológico ocupado pelos diferentes campos de conhecimento, posicionandoos segundo sua afinidade objetiva (DÍAZ \& HELER, 2000). Onde estariam, então, as regiões e lugares de concentração da produção intelectual extensionista na mesma? Onde localizou-se a episteme da extensão rural em meio ao processo de disciplinarização moderna? Atentar-se-á, portanto, para caracterizar os processos de produção e sistematização de conhecimentos no âmbito da prática intelectual extensionista.

Por fim, recair-se-á sobre o desafio epistemológico contemporâneo da extensão rural, de definir o sentido da episteme extensionista a partir das consequências da cientificização das sociedades, ou seja, de entender as relações que emergem a partir desse "tempo de extensão total" ${ }^{1}$, em que uma enorme quantidade de sociedades encontra-se imersa em discursos e conhecimentos cientificamente elaborados e reproduzidos, diluindo, de alguma forma, as estruturas clássicas de produção e transferência de conhecimentos e tecnologias. A tese em questão é a de que muitas sociedades já estão imersas na epistemoontologia científica, ou seja, que as pessoas, em sua maioria, já são formalmente

1 Faz-se menção, aqui, àquilo que alguns autores denominaram de "instituições totais", contudo, neste caso, refere-se ao "tempo da extensão total" como "uma estrutura dos encontros sociais - a estrutura daquelas entidades da vida social que surgem sempre que as pessoas entram na presença física imediata uma das outras" (GOFFMAN, 2002, p. 233). 
educadas e já se apropriaram das bases discursivas científicas. Com isso, essas sociedades e essas pessoas reproduzem-se, cotidianamente, por meio de elementos discursivos, dialéticos e práticos derivados ou reproduzidos pelas construções científicas. Portanto, no contexto atual de mais amplo acesso à informação, conformam-se, em muitas sociedades, interações discursivas, dialéticas e práticas fortemente embasadas pela epistemo-ontologia científica moderna (BAUMAN, 2001). Diluem-se, então, muitas das barreiras que condicionaram, historicamente, as relações extensionistas e conjuntura-se um "tempo de extensão total".

A extensão rural, portanto, atinge outro momento histórico, um momento de mudança que é fruto das próprias transformações vivenciadas pelas sociedades em suas relações com os discursos cultivados e cultuados pelas universidades e instituições afins. Assim, a extensão rural atinge esse momento de renovação e compreensão epistemológica, um momento criado por ela mesma em suas relações com as realidades, um inevitável tempo de mudanças de perspectivas, talvez, tão, inevitável como a criança que, em algum momento, tornar-se-à adulta.

\section{Uma breve arqueologia da extensão rural: os "lugares" da extensão rural na história}

Datam do ano de 1269, as primeiras tentativas de institucionalização da extensão junto às instituições ocidentais formais. Nessa data, a ordem religiosa ocupante do Mosteiro de Alcoçaba, em Portugal, empreendeu uma proposta para a realização de atividades beneficentes relacionadas à assistência por intermédio da botica (a farmácia) e da esmola da portaria. Além disso, registrou-se, nesse período, a abertura da primeira escola pública. Essa iniciativa foi acompanhada pela emergência, junto a grupos eclesiásticos, na busca pela resolução de problemas externos aos "muros" dos espaços institucionais, o que influenciou diretamente na formação das primeiras universidades medievais (ROCHA, 2001).

Se contemplada convencionalmente como um dos primeiros registros em extensão, pode-se destacar que a experiência desenvolvida no Mosteiro de Alcoçaba já tangenciava a construção de uma das mais marcantes perspectivas utilizadas no âmbito da extensão rural - o humanismo assistencialista. Tão antiga quanto contemporânea, é comum a prática extensionista realizada sob esse modelo político-pedagógico. Além disso, o evento em questão registra três características indeléveis do fenômeno da extensão rural: suas raízes acadêmicas, pedagógicas e intervencionistas.

No decorrer dos séculos, algumas universidades medievais se dedicaram, com cada vez mais afinco, para estenderem suas práticas intervencionistas e transformativas conformadas a partir das racionalidades produzidas academicamente e incrementarem suas estruturas pedagógicas, potencializando, com isso, o acesso da população à educação formal. Nessas marcas do tempo, pode-se observar o embrião do que atualmente se reconhece como extensão universitária. Há de se considerar, consequentemente, alguma relação convergente entre essas ações das universidades medievais e a emergência e estabelecimento do que se entende, hoje, principalmente na América Latina, como o tripé indissociável da universidade: pesquisa, ensino e extensão (SAMPAIO, 2004), .

Pode-se perceber, nesses registros históricos, um importante processo de 
institucionalização formal da extensão, ou seja, de construção de matrizes teóricopráticas em torno da ação da universidade nas sociedades. Nesse sentido, destacase, já em 1918, na América Latina, a marcante Reforma Universitária de Córdoba que, além de suas vastas exigências democratizantes, reivindicou que as universidades institucionalizassem formalmente suas estruturas extensionistas (FREITAS NETO, 2011).

Não obstante, é anteriormente, com o advento da modernidade, que contemplar-se-á mais definidamente a emergência do campo de práticas políticopedagógicas que iria gerar elementos centrais para estabelecer esta (re)construção da arqueologia e da epistemologia extensionista. Nesse período, as universidades medievais que dedicavam-se quase que exclusivamente ao ensino observaram a emergência da universidade moderna, mais preocupada em atender às demandas sociais impostas pela revolução industrial. Começaram, segundo Sampaio (2004, p.3), a se preocupar com "a prestação de serviços que deveriam oferecer às comunidades. Foi neste contexto que surgiu a Extensão como atividade da Universidade como instituição". Em meados do século XIX e em contexto de modernização das sociedades, registram-se, nos dois lados do atlântico, movimentos paralelos produzidos pelas universidades inglesas e americanas para o estabelecimento e a institucionalização formal da extensão universitária.

\begin{abstract}
A Extensão Universitária - já com esta denominação - terá sua primeira experiência na Universidade de Cambridge, na Inglaterra, em 1867, por meio de um programa de palestras que, em decorrência do sucesso alcançado, propiciou a institucionalização da Extensão nesta Universidade. A Extensão inglesa irradia-se aos Estados Unidos. Em 1862 o congresso americano aprova a Lei "Justin Smith Morril", que cede terrenos públicos aos Estados e Territórios para a instalação de escolas de agricultura e mecânica, denominadas de Land Grant Colleges. Logo após foram criadas as Escolas Superiores Rurais ou Universidades Rurais2 (SAMPAIO, 2004, p. 3).
\end{abstract}

No contexto da revolução industrial, a ideia da extensão passa a ser explorada com mais intensidade pelas universidades, buscando, com isso, adequar as sociedades para o desenvolvimento de um novo modelo produtivo em construção - a indústria. Nas universidades inglesas, observou-se a emergência de propostas político-pedagógicas que atentavam para suprir a necessidade de preparação técnica dos profissionais para este novo modelo produtivo. De acordo com Sampaio (2004, p.3), a instituição "viu-se obrigada a responder às demandas sociais e a diversificar suas atividades, não ficando limitada à função única de formação das elites". A montante desse processo, constituiu-se o modelo de extensão europeu que, naquele momento, caracterizou-se por proporcionar cursos e serviços técnicos com vistas a atingir uma educação continuada e uma formação técnica.

Nos Estados Unidos da América, essa lógica foi transferida para o mundo rural. A partir das universidades rurais ("Land Grant Universities"), foram pensadas estratégias para o novo modelo de produção - moderno - que também

2 No Brasil, o documento intitulado "Extensão rural no Brasil: uma abordagem histórica da legislação" (PEIXOTO, 2008) conta com detalhes o processo de institucionalização da extensão rural no Brasil e faz referências sobre a influência da criação das universidades rurais brasileiras. 
apresentava-se para o mundo rural. Nesse caso, a educação continuada e a formação técnica também foram priorizadas como forma de estabelecimento e institucionalização da extensão rural. Dois eventos legislativos instituíram as bases para a institucionalização da extensão rural nos Estados Unidos: a Lei "Justin Smith Morril", de 1862, que promoveu a doação de terras para a criação de escolas de agricultura e mecânica (Land Grant Universities) e o "Smith-Lever Act", de 1914, que estabeleceu a criação de serviços de extensão rural junto a estas escolas ou universidades rurais. Um modelo que, inicialmente, associava universidades e serviços extensionistas rurais orientados a transferirem conhecimentos práticos e úteis relacionados à produção agrícola e à economia doméstica, contribuindo para a adoção de novos hábitos e atitudes por meio do uso das tecnologias emergentes (BERGAMASCO, 1983).

Esses serviços de extensão cooperativa ("cooperative extension services") operacionalizavam e promoviam, a partir das universidades rurais americanas, serviços de apoio técnico relacionados à agricultura, à economia doméstica, às políticas públicas, ao desenvolvimento econômico, às lideranças, à produção pesqueira, à juventude rural, etc. Por intermédio das universidades, portanto, instituíram-se formalmente os serviços de extensão rural com objetivos explícitos de impulsionar as ações político-estratégicas de modernização do campo. Ações que, de modo geral, mesclavam práticas assistencialistas e difusionistas (BERGAMASCO, 1983; FIGUEIREDO, 1984).

Nesse processo, pode-se observar a construção de outra marca indelével no conteúdo histórico e epistêmico da extensão rural, suas relações com as inovações. Em um contexto de crença extrema no potencial do projeto científico moderno, universidades e estados imbricaram-se cada vez mais para colocar em marcha seus exercícios de projeção social (MALDONADO, 1971). Consequentemente, observou-se a adoção da educação técnico-científica em praticamente todo o mundo ocidental, em que ficava caracterizada a busca pela substituição dos conhecimentos e práticas tradicionais pelas bases epistemológicas e práticas modernas. Portanto, cronológica e espacialmente pode-se acompanhar a presença da extensão em um sentido centrífugo, ou seja, partindo de sua origem urbana em direção aos espaços rurais, da industrialização urbana para a rural, seguindo um caminho para substituição dos conhecimentos e técnicas modernas em detrimento dos conhecimentos e técnicas tradicionais (FONSECA, 1985; RODRIGUES, 1997).

Esses processos de modernização das práticas sociais, associado ao expoente incremento do uso das inovações tecnológicas, relacionaram-se de forma particular com a extensão rural, introduzindo-se na sua história de forma a compor mais uma das marcas indeléveis no escopo simbólico da extensão rural. Marcas históricas estabelecidas desde as universidades medievais vão se associando à ideia de extensão rural e atribuindo-Ihe relações características com conceitos diversos, como ciência, educação, produção, sociedades, agricultura, comunicação, transformação social, organizações, inovações tecnológicas, modernização, progresso, desenvolvimento, cultura, entre outros. No século XX, portanto, acompanham-se os imensos esforços estatais para realizar o processo de modernização rural, que, por sua vez, resultou no que, atualmente, entende-se como Revolução Verde (BERGAMASCO, 1983; FONSECA, 1985).

Com a busca por compreender os marcantes processos de modernização em ocorrência no mundo rural norte-americano e suas relações com a extensão 
rural, deve-se atentar para as décadas de 1940 e 1950, quando emergem as primeiras pesquisas em difusão de inovações nos departamentos de sociologia rural de várias universidades dos EUA. Posteriormente, já na década de 1960, tais objetos de pesquisas também foram estudados por outras áreas disciplinares como, por exemplo, comunicação, geografia, marketing e economia. Em 1962, é publicada a primeira edição do livro "Diffusion of Innovations" de Everett Rogers (EICHER, 2007).

Cabe destacar a importância para a extensão rural dessas primeiras pesquisas em difusão de inovações realizadas pelos departamentos de sociologia rural das universidades americanas. Podem ser consideradas como embriões do múltiplo campo de estudos que, atualmente, poder-se-ia reconhecer como episteme extensionista. Além disso, entende-se aqui que, para fins de contemplação de um campo de estudos específico, esses configurariam uma linha de estudos clássicos em extensão rural (RÖLING, 2007). O estabelecimento desse ponto de partida torna-se importante para contextualizar os argumentos explicitados na próxima seção, que preza por delimitar uma epistemogeografia extensionista. Nesse processo, contempla-se, portanto, o início da tênue divisão entre o campo de práticas e o campo de estudos em extensão rural, demarcando uma dimensão própria de preocupações epistemológicas.

Por outro lado, no campo de práticas, o processo histórico de institucionalização da extensão rural demonstra que, de forma similar ao ocorrido nos Estados Unidos e embalados pelo contexto de superprodução proporcionada pela utilização de novas tecnologias de produção agrícola e pelos incentivos aportados pela instituição dos organismos internacionais do pós-guerra, as agências de extensão rural assumem proporções diversas e são implantadas em um número expressivo de países. No entanto, a conjuntura apresentada em cada país resulta em uma adaptação estratégica diferenciada para a instituição dessas agências. Na América Latina e em muitos outros países, por exemplo, a fragilidade ou inexistência das universidades fez com que as agências de extensão rural fossem estabelecidas diretamente por intermédio de seus ministérios de agricultura, incidindo, assim, em uma presença fraca em pesquisa. O Brasil, por exemplo, não apresentava as condições ideais para a operacionalização de modelos extensionistas por intermédio das universidades. Entretanto, as universidades e escolas técnicas puderam viabilizar a formação do corpo técnico para o desenvolvimento das instituições e atividades direcionadas à extensão rural (PEIXOTO, 2009). Nesse contexto, universidades e agências de extensão compartilhavam seus modelos político-pedagógicos, cujo objetivo principal e comum era potencializar a modernização agrícola (BERGAMASCO, 1983).

A presença dos organismos internacionais para o desenvolvimento e de entidades filantrópicas financiadoras foi fundamental para a ascensão das instituições de extensão rural. Entre as décadas de 1940 e 1980, a Food and Agriculture Organization (FAO/ONU) assumiu o protagonismo para a difusão global das agências e serviços de extensão rural, desenhando-os e oferecendo recursos e conselhos aos membros dos diferentes Estados para a implantação dos mesmos, baseados, principalmente, nos modelos político-pedagógicos que, na atualidade, reconhece-se como assistencialistas e difusionistas (EICHER, 2007).

No caso brasileiro, por exemplo, há forte correlação com as afirmações colocadas no parágrafo anterior. Além disso, destaca-se o suporte proporcionado 
pela entidade filantrópica Associação Internacional Americana - AIA, ligada à família Rockfeller, para a criação, em Minas Gerais, da primeira Associação de Crédito e Assistência Rural - ACAR, em 1948. Posteriormente, em 1954, acordouse entre os governos brasileiro e americano o Projeto Técnico de Agricultura - ETA, "visando uma cooperação técnico-financeira, para execução de projetos de desenvolvimento rural, entre os quais se destacava a coordenação nacional das ações de extensão rural" (PEIXOTO, 2008, p. 18) .

Além disso, nesse mesmo período, os países em desenvolvimento foram incentivados pela comunidade financiadora internacional a criar centros de pesquisas de referência internacional, atentando principalmente para seus problemas de segurança alimentar. $O$ intuito central era de "fornecer o suporte técnico e apoio aos centros de pesquisa agrícola nacionais" (PEIXOTO, 2009, p. 2).

A extensão rural, portanto, projetava-se como instituição formal mundialmente reconhecida para apoiar uma das maiores transformações observadas na história da agricultura, a modernização agrícola. A extensão rural conquista, com isso, seus "lugares na história". Ciência, pedagogia, intervenções político-estratégicas e inovação associados ao contexto histórico de ruralização das práticas extensionistas vão configurando-se como marcas indeléveis de seu escopo conceitual e prático (FREIRE, 2006).

Sem embargo, na década de 1970, as clássicas abordagens - assistencialista e difusionista - começavam a dar lugar, paralelamente, a distintas abordagens e estruturações institucionais. Para minimizar as limitações e as consequências indesejadas da difusão de inovações, produziu-se a ascensão de novos modelos político-pedagógicos, entre os quais se destacam a ideia de Desenvolvimento Rural Integrado - DRI, os sistemas de Treinamento e Visita (T\&V) e a oferta de pacotes de serviços integrados (pesquisa agrícola, crédito rural, extensão rural e comercialização). Além disso, na década de 1980, com o movimento ideológico de afastamento dos modelos lineares de transferência de tecnologias e das abordagens impositivas quanto ao fluxo de informações entre cientistas e agricultores ("de cima para baixo"), observa-se também a emergência das metodologias participativas, de discussões de gênero e de preocupações ambientais (FEDER; WILLETT \& ZIPJ, 1999).

Desse modo, pode-se contemplar que posteriormente a esse período de estruturação e institucionalização da extensão rural embasada nas abordagens assistencialistas e difusionistas, ocorrida entre as décadas de 1920 e 1970, há um período de multiplicação das abordagens político-pedagógicas. Tal período, por sua vez, é observado como uma consequência de uma fase crítica em extensão rural, a qual potencializou a construção de abordagens que superassem os problemas constatados por meio do uso das abordagens extensionistas clássicas. No Brasil, por exemplo, Rodrigues (1997) e Caporal \& Ramos (2006) identificam quatro períodos históricos da extensão rural:

- humanismo assistencialista (1948-1962);

- difusionismo produtivista (1963-1984);

- humanismo crítico (1985-1989);

- ambientalismo agroecológico (atual).

Cabe destacar que o citado momento de multiplicação das abordagens político-pedagógicas coincide com um período significativo de hegemonia do pensamento neoliberal nos governos estatais e dos organismos internacionais 
ocorrido no final da década de 1970. Desse modo, observou-se a diminuição dos suportes estatais e institucionais que potencializavam a continuidade das atividades extensionistas sob as matrizes construídas historicamente. No Brasil, por exemplo, o início da década de 1990 ficou marcada pelo fechamento da agência estatal de extensão rural, a EMBRATER. Não obstante, a crise estrutural promoveu processos de reflexão profunda sobre as dinâmicas extensionistas, de observação das consequências positivas e negativas da revolução verde, bem como de busca, reconhecimento e construção de discursos, diálogos e práticas alternativas (RODRIGUES, 1997; CAPORAL \& RAMOS, 2006).

Apesar do enfraquecimento das estruturas estatais relacionadas à extensão rural, a literatura indica a continuidade no processo de incremento 3 do contexto institucional da mesma, ocasionada, principalmente, pelo fenômeno do pluralismo institucional (DIESEL et. al., 2008). A emergência de empresas privadas e de terceiro setor impulsionadas pelas diretrizes neoliberais do Estado, potencializaram a presença de distintas instituições que passaram a atender às políticas estabelecidas pelos mesmos. Observa-se, com isso, a busca pela constituição de redes multi-institucionais de manutenção de conhecimento e informação para as sociedades rurais, a qual prezaria por uma agenda mais ampla de desenvolvimento rural (RIVERA \& ALEX, 2004). De acordo com Peixoto (2009, p.9), "isto implica que os governos precisam atuar na definição e na execução de uma política coerente de extensão em direção a um sistema pluralista de serviços".

Como se viu até aqui, a arqueologia da extensão rural permitiu que se observasse os principais momentos históricos da trajetória extensionista em seu caminho de institucionalização formal, possibilitando refletir sobre sua emergência assistencialista no medievo; sobre sua reconfiguração moderna e a consequente imersão rural; sobre sua crença nas inovações e no projeto moderno; e, por fim, sobre sua multiplicação de abordagens que conformam as contemporâneas posturas e estratégias político-pedagógicas extensionistas. O contexto atual, portanto, apresenta uma enorme diversidade de opções epistemológicas. Já o passado, não obstante, evidencia que a des-coberta da episteme extensionista emerge em um momento específico: as clássicas pesquisas em difusão de inovações realizadas no âmbito dos departamentos de sociologia rural das universidades americanas. É lá que a extensão rural estabelece suas primeiras marcas na plataforma epistemológica moderna.

São marcas que se estabelecem, nessa plataforma, muito mais próximas das ciências humanas e sociais do que das ciências naturais e exatas. Não obstante, são marcas caracteristicamente genuínas que, com o tempo, ocuparam um espaço epistemológico próprio, explícito e, por isso, capaz de ser expressado, como no caso deste trabalho. Apesar de seus vínculos históricos, não há mais referência aos vieses rurais da sociologia, da administração, da economia, da antropologia, da comunicação, da psicologia, etc. Resultante das derivações dos processos disciplinares e historicamente imersa em escolhas epistemológicas relacionadas às

3 De acordo com Anderson \& Feder (2003), há um incremento significativo no número de agentes extensionistas no mundo, que contava com 555 mil agentes em 1987 e com 800 mil agentes no ano de 1997. Ademais, havia uma estimativa apresentada pela FAO, em 1995, através do informe intitulado "Agricultura Mundial: até o ano 2010" que indicava a necessidade de contar, para a data em questão, com a presença de 2,4 milhões de extensionistas trabalhando para 0 desenvolvimento rural. 
ciências humanas e sociais, a extensão rural conquista um espaço epistemológico próprio nessa plataforma moderna.

Nesse contexto, entende-se que é necessário explorar brevemente o posicionamento das ciências humanas e sociais frente ao processo de estruturação epistemológica moderno, ilustrando, deste modo, a construção e a emergência dos "lugares" da extensão rural na epistemologia moderna.

\section{Epistemogeografia em extensão rural: os lugares da extensão na epistemologia moderna}

Os epistemólogos Díaz \& Heler (2000), por meio de uma análise epistemológica de inspiração foucaultiana, potencializam a emergência do que aqui se denomina de epistemogeografia, ou seja, constituem uma linha analítica capaz de fornecer um mapeamento da estrutura ou, como aqui se refere, da plataforma epistemológica moderna. Assim sendo, o percurso escolhido neste ensaio para a des-coberta da episteme extensionista identifica, na proposta estabelecida pelos epistemológos supracitados, um fértil cenário para a contemplação dos "lugares" da extensão rural na mesma.

O percurso, portanto, perpassa, inicialmente, pela contemplação metafórica dessa territorialização epistemológica, com vistas a identificar genericamente a emergência dessa plataforma moderna de produção e sistematização de conhecimentos. $\mathrm{E}$, posteriormente, por localizar as formas de inserção epistêmica da extensão rural na mesma, ou seja, identificando os lugares e regiões da produção e sistematização de conhecimentos reconhecidamente relacionados à extensão rural nessa plataforma ou mapa.

Conforme delimitou-se na seção anterior deste ensaio, identifica-se que a construção de uma episteme extensionista passa pela emergência, na década de 1940, dos clássicos estudos em difusão de inovações realizados pelos departamentos de sociologia rural das universidades americanas em contexto de modernização agrícola. Estes, por sua vez, estruturaram-se em torno das práticas intelectuais proporcionadas pela ascensão das ciências humanas enquanto leitura epistemológica moderna. Portanto, encontrar os lugares da extensão rural nessa plataforma faz parte, também, de um exercício de compreensão da epistemologia moderna, bem como dos seus processos de transcendência.

Para tentar contribuir no alcance de tal compreensão, Díaz \& Heler (2000) buscam elaborar, inspirados na perspectiva genealógica foucaultiana, um mapeamento das ciências humanas a partir da institucionalização da episteme moderna. Propôem, portanto, uma terceira via de análise epistemológica para as ciências humanas, em que se preza pela ruptura dicotômica estabelecida entre o reducionismo e o não-reducionismo. Para tal, explorar-se-á sua série de ilustrações que tentam demonstrar, de forma mais palpável, os pontos de concentração e de disciplinarização moderna, explicitando, com isso, uma região epistemológica básica para a construção dos exercícios metaepistemológicos típicos das ciências humanas.

Nesse contexto, a ilustração 1 introduz uma primeira demonstração da estruturação epistêmica moderna em que fica caracterizada claramente uma separação relacionada à capacidade positiva de cada atividade intelectual. Igualmente, revela uma breve estruturação relacionada ao processo de promoção 
da expansão disciplinar moderna.

Ilustração 1. Estruturação foucaultiana da perspectiva epistemo-ontológica moderna

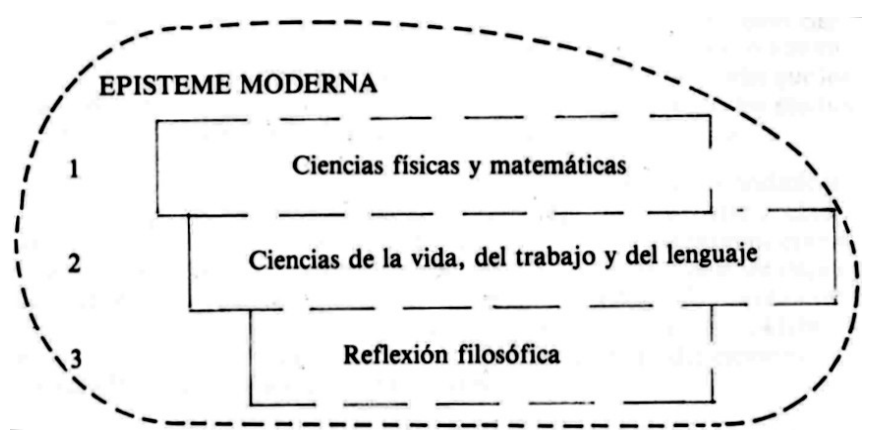

Fonte: Díaz \& Heler (2000).

Conforme destacam Díaz \& Heler (2000), a análise foucaultiana disponibiliza a percepção dos domínios da episteme moderna concentrando-se basicamente entre três dimensões. Separadas por penetráveis linhas pontilhadas, apresenta-se uma dimensão dominada pelas ciências físicas e matemáticas, ordenada pelos exercícios de dedução; em outra dimensão distribuem-se as ciências que relacionam-se com a vida, a linguagem e o trabalho; por fim, há uma terceira dimensão que se dedica à reflexão filosófica, ou seja, direcionando-se as derivações do pensamento sobre a questão do Ser (DÍAZ \& HELER, 2000).

Como se pode observar na ilustração 1, não há explicitamente uma localização definida para as ciências humanas, tampouco há para a sociologia rural e para a extensão rural. O que há, em consequência de uma definição excludente de campos de estudos próprios, é a promoção de interstícios e espaços de construção intelectual que incidem na configuração de uma dimensão para as ciências humanas disposta externamente ao núcleo epistemológico moderno.

Desse triedro epistemológico, as ciências humanas são excluídas, no sentido ao menos em que não podem ser encontradas em nenhumas das dimensões, nem à superfície de nenhum dos planos assim delineados. Mas, pode-se também dizer que elas são incluídas por ele, pois é no interstício desses saberes, mais exatamente no volume definido por suas três dimensões, que elas encontram seu lugar (FOUCAULT, 1999, p. 480).

Nesse contexto, destaca-se as ciências que compartilham seus domínios entre o matematizável e o não matematizável, conformando através dos limites da empiria determinados universos de generalizações que diferenciam-se do que se pode denominar ou referenciar como ciências humanas (FOUCAULT, 1999). A biologia, por exemplo, como ciência que trata diretamente de temas que tem a ver com a vida, não limita-se apenas aos aspectos humanos da vida, mas também das distintas formas de vida. Apesar de concentrar-se nos aspectos matematizáveis da vida, há tempos a biologia vem utilizando relações causais em suas matematizações. Uma clássica, não seria a teoria da seleção natural? 
Já no âmbito das ciências que tratam dos aspectos relacionados ao trabalho, institucionalizaram-se, dentro da perspectiva econômica ocidental, formas observáveis de estabelecer aspectos sobre o ser humano como espécie que trabalha. Apesar de ser considerada, geralmente, como ciência humana, a economia elaborou um modo especial e matematizável para dar conotação diferenciada às questões relativas à produção, à distribuição e ao consumo. Ou seja, representando o ser humano enquanto formas de satisfação de suas necessidades, neste caso, invadindo também diversas relações causais, por exemplo, a especulação.

Logo, no âmbito das ciências que tratam das questões relacionadas à linguagem, estabeleceu-se, por meio da linguística, uma abordagem empírica para representar a linguagem humana. A linguística encontrou seu objeto de estudo nos sistemas de signos, nas relações sintáticas, semânticas e pragmáticas, entretanto, não se estabeleceu tanto na representação do ser humano como linguagem. Desse modo, a linguística pode ou não adentrar ao contexto das ciências humanas.

As ciências humanas, por sua vez, ganham forma nesse contexto de extrapolação das relações causais proporcionadas pelas ciências da vida, do trabalho e da linguagem. Ou seja, em uma dimensão que extrapola os aspectos matematizáveis e configuram formas diferenciadas e múltiplas de empiria em que o ser humano pode explorar suas relações para além dos aspectos morfológicos e fisiológicos.

Todavia, não foi em suas relações com as matemáticas que a biologia assumiu sua autonomia e definiu sua positividade. O mesmo ocorreu com as ciências humanas: foi o retraimento da máthêsis e não o avanço das matemáticas que permitiu ao homem constituir-se como objeto do saber; foi o envolvimento do trabalho, da vida e da linguagem em torno deles próprios que prescreveu, do exterior, o aparecimento desse novo domínio; e é o aparecimento desse ser empírico-transcedental, desse ser cujo pensamento é indefinidamente tramado com o impensado, desse sempre separado de uma origem que lhe é prometida na imediatidade do retorno - é esse aparecimento que dá às ciências humanas sua feição singular (FOUCAULT, 1999, p. 484).

Michel Foucault (1999) utiliza-se das palavras reduplicação, vizinhança e exterioridade para expressar a relação entre as ciências humanas e a biologia, a economia e a linguística, exercícios intelectuais conformantes de uma região metaepistemológica na qual concentram-se as ciências humanas e sociais. A ilustração 2 busca tornar visíveis as considerações expressadas acima, identificando, deste modo, uma dimensão de construção das ciências humanas. 
Ilustração 2. Mapeamento de inspiração foucaultiana relativo a emergência das ciências humanas

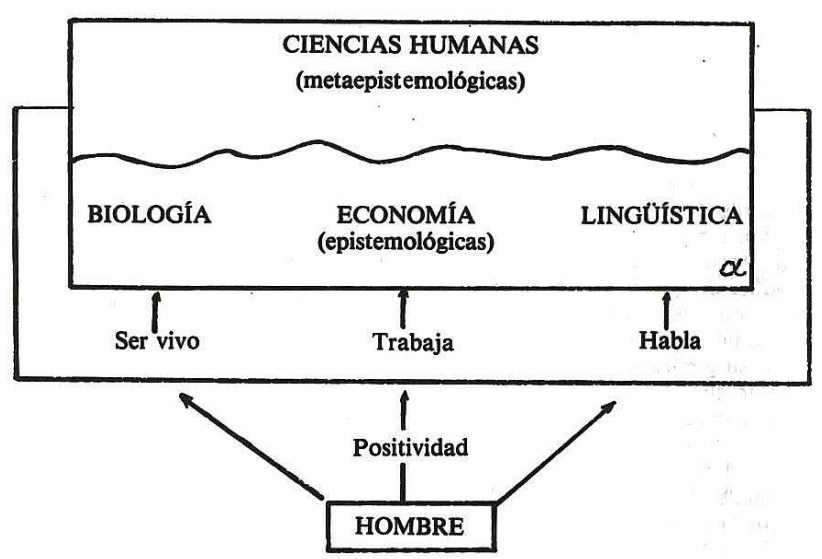

Fonte: Adaptado de Díaz \& Heler (2000).

A epistemologia em extensão, com isso, participa igualmente desse processo de construção das ciências humanas, concentrando seus estudos, também, nas relações causais dessas representações derivadas da região epistemológica construída entre as ciências que tratam da vida, do trabalho e da linguagem. Uma região metaepistemológica que, por sua vez, pode ser melhor visualizada no mapa epistemológico ilustrativo destacado abaixo pela ilustração 3.

Ilustração 3. Regionalização epistemológica exemplificativa de inspiração foucaultiana para as ciências humanas

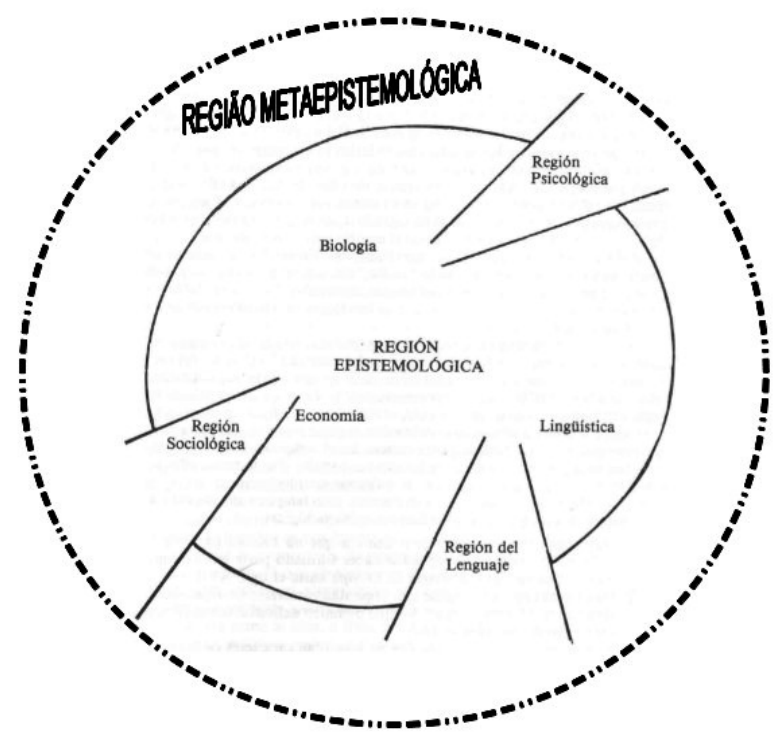

Fonte: Adaptado de Diaz \& Heler (2000). 
Contudo, deve-se destacar que as ilustrações utilizadas para configurar um mapeamento das ciências humanas representam, de forma geral, uma proposta genealógica para a compreensão destas em seu contexto de institucionalização e até de aceitação junto às atividades científicas ou intelectuais. Portanto, a contemporaneização desse mapeamento levaria a uma configuração mais complexa de ilustração dos lugares onde encontram-se atualmente as ciências humanas. Estas, avançando praticamente sem limites nos exercícios de reduplicação e, por sua vez, configurando inclusive relações e inovações disciplinares ímpares, interdisciplinares, transdisciplinares, etc. Isso é o que buscase representar na ilustração 4, a qual apresenta espaços concernentes com 0 processo de transdisciplinarização das ciências.

Ilustração 4. Regionalização epistemológica de inspiração foucaultiana em contexto de expansão disciplinar contemporânea

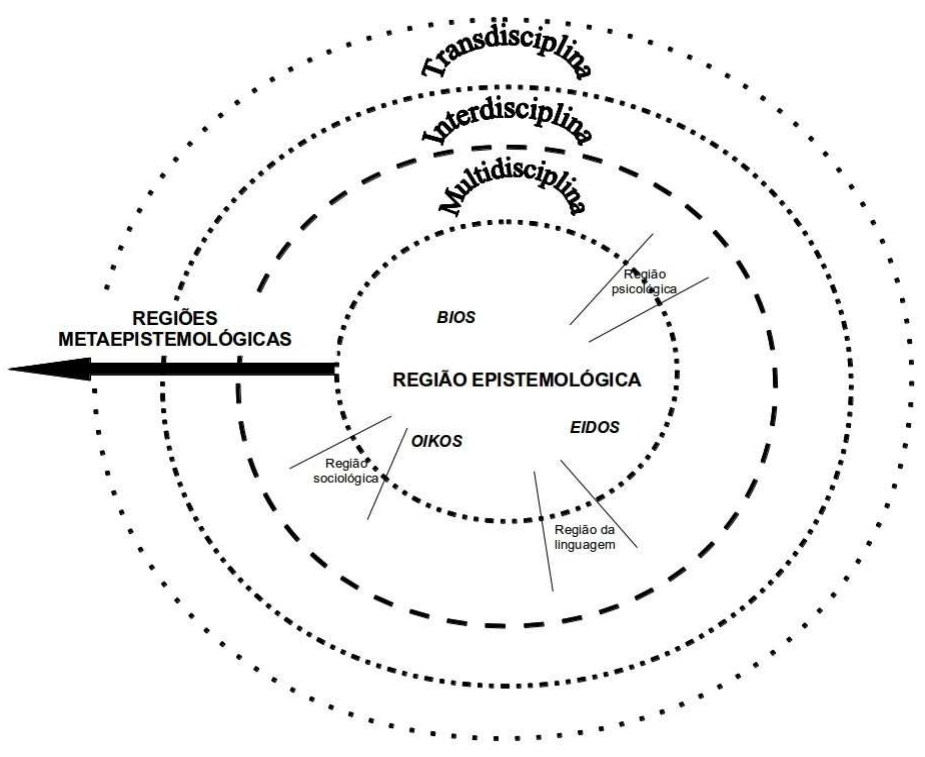

Fonte: Elaboração própria.

É por isso que o específico das ciências humanas não é o direcionamento a certo conteúdo (esse objeto singular que é o ser humano); é muito mais um caráter puramente formal: o simples fato de estarem, em relação às ciências em que o ser humano é dado como objeto (exclusivo para a economia e a filologia, ou parcial para a biologia), numa posição de reduplicação, e de que essa reduplicação possa valer a fortiori a elas mesmas. [...] Em relação à biologia, à economia, às ciências da linguagem, elas não estão, portanto, em carência de exatidão ou de rigor; estão antes, como ciências da reduplicação, numa posição "metaepistemológica" (FOUCAULT, 1999, p. 490).

\section{A construção da episteme extensionista: o caminho entre o discurso, o diálogo e a práxis}

É esse processo de reduplicação que dá forma e características próprias às 
práticas intelectuais observadas nas ciências humanas e sociais que potencializou também, na década de 1940, a emergência daqueles citados estudos clássicos em extensão rural produzidos pelos departamentos de sociologia rural das universidades americanas. Contudo, é principalmente o modo com que são realizadas essas reduplicações que dá caráter particular aos mesmos, disponibilizando, por meio do estudo de difusão das inovações, uma proposta metodológica para explicitar os fenômenos derivados do processo em questão. De modo geral, pode-se identificar que, em torno daquele emergente processo de difusão de inovações, havia um discurso, um campo semântico e simbólico atrelado à modernização agrícola; havia também uma proposta dialógica, um modelo político-pedagógico de referência para o diálogo social, neste caso, difusionista; ademais, havia a práxis, transformações práticas vivenciadas pelas sociedades rurais associadas aos acima citados discursos e diálogos.

Esse modo particular de reduplicação, por sua vez, pode ser observado tanto no campo de estudos, como no campo de práticas extensionistas. O discurso, o diálogo e a práxis congregam, com isso, aquilo que poder-se-ia denominar de indissociável tríade metodológica extensionista. De modo exemplificativo, explorar-se-á, a seguir, a forma com que os clássicos intelectuais extensionistas estabeleceram seus estudos por meio dessa tríade.

O conceituado intelectual extensionista Niels Röling (2007) apresenta um breve resgate histórico que trata sobre os estudos extensionistas teoricamente mais expressivos. Nesse resgate, evidencia-se a riqueza de processos sociais que emergiam durante o período de modernização agrícola americana como sendo um terreno fenomenologicamente fértil para o estabelecimento de diversas relações que potencializavam-se por meio das transformações sociais observadas no campo. As consequências da difusão das inovações agrícolas "saltavam aos olhos" de pesquisadores daquelas universidades americanas e seus departamentos de sociologia rural foram os primeiros a explicitá-las.

Dentre os mesmos, o fenômeno da "roda imparável da produção agrícola", apresentado pelo economista rural Willard W. Cochrane, em 1958, pode ser simbolicamente considerado como um dos primeiros estudos em extensão rural. Cochrane (1958) analisou as consequências de aplicação do discurso de desenvolvimento agrícola americano a partir do estabelecimento das commodities agrícolas e identifica, na luta dos agricultores pelo aumento da produtividade e redução dos custos de produção, um processo de (re)concentração fundiária por meio da exclusão dos mesmos decorrente das dinâmicas de adoção das inovações. Nesse caso, pode-se observar que Cochrane percebe que o discurso em questão, colocado em prática através de matrizes político-pedagógicas difusionistas, apresenta índices de adoção heterogêneos pelos agricultores fazendo com que a práxis estabelecida no processo de modernização agrícola promova vantagens competitivas para alguns e exclusão para outros. Seu estudo, portanto, atenta categórica e explicitamente para estabelecer uma relação entre o discurso, o diálogo e a práxis. Trabalha, assim, nos interstícios da plataforma epistemológica moderna, construindo caminhos entre as distintas disciplinas.

Contemporaneamente a Cochrane, foi publicado, em 1962, o mais famoso dos estudos em extensão rural, a "Difusão de Inovações", de Everett Rogers, o qual teve nome inspirado no difusionismo, teoria de diálogo intercultural muito comum no século XVIII. Também sob o cenário do discurso de desenvolvimento 
agrícola americano e corroborando os estudos de Cochrane, Rogers estabeleceu estudos que realizavam a leitura da dinâmica de adoção das inovações, prezando por identificar como os agricultores reagiam às mesmas e vivenciavam, com isso, uma dinâmica heterogênea de adoção. Imerso em matrizes cognitivistas, o autor busca explicitar os perfis e as características dos agricultores em relação à apropriação discursiva, dialógica e prática das inovações agrícolas. Observa, desse modo, inúmeros estudos que confirmam suas teses em relação à difusão de inovações, entre estes, poder-se-ia destacar os trabalhos sobre a adoção das sementes de milho híbrido (RYAN \& GROSS, 1943) que, por fim, também serviu de base para estabelecer o método político-pedagógico difusionista4.

Da mesma forma que Cochrane, Rogers (2003) estabeleceu seus fenômenos através de uma leitura da difusão de inovações imersa na tríade discurso-diálogo-práxis. Nesta, prezou por enfatizar as condições psicológicas que influenciavam para a adoção das inovações pelos agricultores em termos individuais e coletivos. Entre os temas mais destacados, pode-se citar suas análises sobre os aspectos das lideranças de grupos, das redes de inovações, das características das inovações e suas influências para a adoção, dos métodos persuasivos, entre outras.

Dando continuidade a essa linha clássica, ainda poder-se-ia destacar uma terceira via de estudos em extensão rural denominada de transferência de tecnologias, estabelecida na década de 1980 (HAVELOCK, 1986 apud RÖLING, 2007). Tanto a abordagem em questão quanto a mais atual abordagem de estudos em "Sistemas Agrários" (MAZOYER \& ROUDART, 2010), mantinham o caráter clássico de compreender as particularidades emergentes das relações estabelecidas entre os agricultores e seus sistemas produtivos modernos, atentando por referenciar tecnicamente as decisões de usos dos sistemas (RÖLING, 2007).

Como se pode observar, os estudos em extensão rural promovidos durante o período de intensa crença no projeto moderno eram principalmente de cunho transformativo, ou seja, dedicavam-se quase que exclusivamente a observar o âmbito da práxis, visto que poucas dúvidas se tinha em relação aos discursos e métodos político-pedagógicos. Com isso, os estudos derivavam de diálogos praticamente unilaterais, em que a preocupação centrava-se em como os produtores reagiam às propostas técnicas inovadoras difundidas nas sociedades rurais. Entretanto, com a crise epistemo-ontológica do paradigma moderno, outras perspectivas e abordagens começaram a influenciar sobre os estudos em extensão, assim como nas demais áreas. Inclusive, levando os mesmos a diferenciarem-se das posturas em que traçavam suas perspectivas, tentando escapar, com isso, dos pressupostos que figuravam em grande parte da produção realizada no contexto do projeto moderno como, por exemplo, de progresso e crescimento econômico. As principais críticas se deram, então, no âmbito da dinâmica das interações culturais e socioambientais (ESCOBAR, 2010).

4 A partir de seu estudo da difusão de inovações, Everett Rogers (2003) estabeleceu as bases do modelo linear difusionista. Seu modelo político-pedagógico propõe algumas etapas básicas para facilitar a adoção das inovações pelos agricultores, são estas: conhecimentopersuasão-decisão-implementação-confirmação. 
O Curso de Pós-Graduação em Extensão Rural da Universidade Federal de Santa Maria - UFSM, fundado no ano de 1975, com nível mestrado, apresentou grande influência sobre a ascensão dos estudos com tal abordagem, pois tornou-se pioneiro na América Latina em propô-los e assumi-los enquanto estudo em extensão rural. Fato que demonstra, invariavelmente, a necessidade de direcionarse para compreender melhor as interações entre a tríade discurso-diálogo-práxis a partir das produções científicas e do projeto moderno. Desde a década de 1980, reinterpretam-se, com mais força, as práticas discursivas, dialógicas e a práxis no campo de estudos em extensão. Ademais, a extensão avançou para outras áreas, além dos estudos rurais, convergindo, assim, para um deslocamento aparente dos estudos em direção à compreensão dos elementos discursivos das ciências, passando por momentos de problematização acerca dos diálogos e da práxis, ou seja, por abordagens mais críticas em relação ao seu caráter transformativo, os quais se prezam por reconhecer as demais formas de construção de conhecimento desenvolvidas pelas sociedades. Essa corrente tem sido denominada de "coconstrução do conhecimento", que como o próprio nome já diz, busca, teoricamente, a construção dos discursos, diálogos e da práxis por meio de modelos político-pedagógicos não exclusivamente científicos como, por exemplo, as propostas dialéticas, participativas, libertadoras, interculturalistas e socioambientalistas, de reciprocidade, entre outras (SOUSA SANTOS, 1988; CHAMBERS, 1995; FREIRE, 2006; ESCOBAR, 2010; SABOURIN, 2011).

Ao realizar um estudo sobre as dissertações apresentadas entre as décadas de 1970 e 2010 pelo Programa de Pós-Graduação em Extensão Rural (UFSM), Moraes (2013) defende a tese de que ocorreu um processo de revolução científica nesta comunidade acadêmica ${ }^{5}$, em que os intelectuais superaram a crise paradigmática do modelo clássico difusionista para, logo, assumir um modelo mais próximo do que denominamos de "co-construção de conhecimento", no caso desta comunidade, de emergência de um modelo agroecológico. Observa-se, assim, que a citada comunidade acadêmica passou a contemplar as experiências sociais realizadas por meio de outras matrizes discursivas, dialógicas e práticas.

Explicitam-se estudos em extensão, desse modo, que têm alterado o sentido e a proporção de sua intencionalidade. Por exemplo, as abordagens modernas desses estudos prezavam, principalmente, pela compreensão da capacidade de adaptação social aos mecanismos e processos tecnológicos, na intenção de promovê-los, enquanto que os estudos contemporâneos focam-se, principalmente, nas distorções promovidas pelo escopo dos discursos modernos, no sentido de criticá-los e superá-los, explicitando posturas menos crentes quanto aos conhecimentos e discursos científicos (RÖLING, 2007).

Estabelecida paralelamente à supracitada linha clássica, a abordagem de "co-construção do conhecimento" associada à extensão rural conta com um múltiplo conjunto de modelos político-pedagógicos. Dentre tantos, poder-se-ia destacar os modelos populares (freirianos), participativos, agroecológicos, interculturais, relativistas, a ecologia de saberes, etc. Portanto, de modo geral, observam-se processos de ressignificação em relação aos discursos, neste caso, de destituição da capacidade panaceica do projeto moderno; em relação aos diálogos,

5 O trabalho de Moraes (2013) refere-se à ideia de revolução científica através da ótica apresentada por Thomas Kuhn (1992). Em "A estrutura das revoluções científicas", o autor elenca as etapas sucessórias para a mudança paradigmática em qualquer comunidade científica. 
no sentido de diminuir a unidirecionalidade dialógica outrora tendo ponto de partida somente os discursos e práticas científicas; e, por fim, em relação à práxis, com vistas a contemplar e (re)valorar as práticas populares e tradicionais.

A prática intelectual extensionista tangencia, na atualidade, também uma dimensão antropológica, mais especificamente, uma antropologia da ciência. Esses processos de ressignificação evidenciam, de modo geral, homem, natureza e cultura subtraídos pelo mito da neutralidade científica. É possível observar, por exemplo, a força do discurso científico em neutralizar os diálogos e práticas sociais culturalmente diferenciados. Faz-se necessário também entender os fenômenos que emergem da cientifização das sociedades. Como são suas instituições, suas entidades, seus rituais, sua vida cotidiana? Como expressa-se a natureza e a cultura? Quem somos nós, cientistas-cidadãos? É necessário à extensão rural (re)interpretar a ciência enquanto discurso, diálogo e práxis.

Um estudo sobre os princípios ontológicos que utilizam os extensionistas para o planejamento e execução de projetos de desenvolvimento rural, apresentado por Lima (2001), destaca que, na análise de 74 casos, nenhum deles utilizou-se de matrizes crítico-dialéticas $(0,0 \%)$. Em 17,92\% foram observadas características fenomenológico-hermenêuticas e em $81,08 \%$ dos casos reproduziram-se modelos político-pedagógicos empírico-analíticos, que prezam por atentar para os fenômenos derivados da técnica e da informação, de identificar como conhecimento "o interesse técnico de controle e como tipo de mudança proposta, a 'melhoria' do sistema pela sua melhor eficiência e eficácia, ou seja, a manutenção do paradigma da modernização conservadora" (LIMA, 2001, p. 83). Nesse contexto, ainda há uma primazia pela realidade material e objetiva que, segundo Lima (2001, p.86), é entendida, no caso estudado, como um "sistema regido por leis, que tende ao equilíbrio e ao repouso, cabendo ao homem descobrir estas leis de seu funcionamento. O homem nessas abordagens é visto como um sujeito passivo, produto do sistema".

Há ainda, portanto, uma herança significativa das perspectivas clássicas no âmbito da prática extensionista. Não obstante, já é legítima a construção de caminhos entre as diferentes regiões epistemológicas, reconhecendo que há amplas possibilidades de estudos em extensão, ou seja, é possível traçar caminhos distintos entre as regiões epistemológicas e seus interstícios.

\section{O tempo da extensão total: uma proposta metodológica}

A leitura histórica dos processos de emergência da extensão demonstra sua relação intrínseca com a universidade. Desse modo, as transformações da mesma refletem sobre os aspectos epistemo-ontológicos dos estudos em extensão. A relativização das crenças no escopo discursivo acadêmico, por sua vez, tem sido fundamental para a compreensão e desenvolvimento de uma epistemologia em extensão. A extensão, nas sociedades modernas, está praticamente em toda parte. $\mathrm{Na}$ cotidianidade ocidental, acompanha-se a presença massiva dos discursos e tecnologias científicas. Ou seja, a vida social moderna constrói-se quase que integralmente através da plataforma epistemo-ontológica científica. 
Operários, médicos, recicladores, engenheiros, agricultores, professores, crianças, adolescentes e adultos das sociedades modernas não estariam vivendo suas vidas, em grande parte, por meio da plataforma epistemo-ontológica científica? Não seria essa plataforma a principal referência para o convívio social nas sociedades modernas? Não seríamos, praticamente, todos extensionistas? $\mathrm{Na}$ estrutura dos encontros sociais, não surgiriam, quase sempre, as entidades extensionistas?

Díaz \& Heler (1997) observaram e explicitaram essa diluição da estrutura clássica extensionista, em que prezava-se pelo modelo linear de transferência de tecnologias. Os autores identificaram, por meio da crescente cientifização das sociedades, um processo de transversalização em ocorrência nesta estrutura, o qual se expressa na deslinearização da mesma, em que as partes reconhecidas do modelo clássico não seguem seu fluxo linear, e sim recebem a influência simultânea e transversal dos processos em andamento nas diferentes contextos sociais.

Nessas sociedades, portanto, de extensão total, não há um novo lugar para a extensão, o que há é uma mudança drástica de perspectivas sobre seus discursos, formas de diálogo e sua práxis. Os estudos em extensão seguem em seu lugar, no âmbito das regiões metaepistemológicas, entretanto, agora são ressignificados a partir da identificação do processo de cientificização das sociedades e da relativização do projeto moderno (HARVEY, 1999).

A extensão rural, com isso, segue sua histórica tríade indissociável que compreende o discurso, o diálogo e a práxis, contudo, agora ressignificados. O discurso científico já não emerge agora como o bradar dos deuses, este pode e deve ser problematizado, analisado, interpretado, autocriticado; o diálogo extensionista não pode mais ser uma via de mão única, deve-se abrir espaço para processos dialógicos abertos, menos imponentes e menos proselitista; a práxis, por sua vez, não pode contemplar somente o outro, mas também deve conter elementos autotransformativos, autopoiéticos e autocríticos. A universidade já não pode ser somente de "dentro para fora", pois o próprio "fora" já está "dentro".

Uma epistemologia em extensão, portanto, é desenhada por meio da tríade discurso-diálogo-práxis, associando e duplicando, com isso, elementos das ciências da vida, do trabalho e da linguagem. Não obstante, deve-se levar em consideração que a contemporaneidade científica já não limita essas ciências apenas à biologia, à economia e à linguística. O que se vizualiza nas construções científicas são dimensões não tão disciplinares para a reduplicação, as quais poderiam ser denominadas mais abertamente, nas formas gregas, de bios, oikos e eidos, respectivamente (ilustração 4). Os estudos em extensão contemplam, simultaneamente, essas três dimensões. De modo geral, busca-se entender como os universos abstracionais atravessam transversalmente as relações sociais $e$ expressam-se, por sua vez, no cotidiano humano.

Não se trata, desse modo, de limitar-se a apresentações de projeções e discursos, de explicitar as particularidades aparentes das redes sociais e de seus participantes. Nem, tampouco, trata-se apenas de explorar detidamente as representações relacionadas à experiência humana. Os estudos em extensão rural, por meio de sua construção histórica, têm se utilizado, simultaneamente, de todas essas plataformas. Sua singularidade, com isso, é determinada por essa explícita transdisciplinaridade apresentada em seus estudos, os quais transitam, 
historicamente, sobre os caminhos que interligam as construções discursivas e o cotidiano humano, pressupondo a existência, entre estes, de fenômenos dialógicos.

Nesse contexto, seu espaço epistemológico permite movimentar-se tanto sobre as disciplinas que avançam nos aspectos mais aparentes como sobre aquelas que dedicam-se às profundezas das relações e das experiências humanas. A grande particularidade seria apresentar uma construção epistemológica que comunique, por meio da análise dialógica, estas distintas dimensões. Ou seja, permite deslocar-se através das regiões metaepistemológicas para apresentar os incríveis fenômenos derivados da interação entre as abstrações científicas e o cotidiano humano.

Com isso, tem-se observado uma predisposição mais etnológica e psicológica, mais especificamente de uma aproximação às sociologias compreensiva (WEBER, 2001) e reflexiva (BOURDIEU, 2007), e é através desses novos olhares que a extensão alcança seu ponto de mutação. A relativização das crenças sobre as projeções e discursos científicos e, consequentemente, sobre o projeto moderno, já presente em Weber, possibilitou aprofundar a problematização dos aspectos relacionados aos mesmos e explicitar o ethos científico. Simultaneamente, as sociedades foram, cada vez mais, incorporando-o em suas distintas realidades. As sociedades modernas foram, paulatinamente, sendo tomadas por esse ethos. Suas características, por sua vez, já não se limitam aos aspectos aparentes do cotidiano humano. Estão presentes até nas profundezas de sua experiência, introduziram-se em diversos campos e habitus socioculturais.

Incrível e surpreendentemente dependente da criatividade intelectual de explorar este ethos, os estudos em extensão rural têm transitado principalmente entre os limites do explícito e do implícito, sistematizando, com isso, suas particularidades no contexto da experiência humana. Coloca-se em evidência o diálogo derivado desse ethos. Tangencia-se tanto o instituído como o impensado.

Ao mesmo tempo, não se trata puramente de utilizar, por exemplo, os métodos etnológicos e as teorias psicanalíticas, mas de relacioná-los na busca de explorar aquilo que proporcionou que se desenvolvessem e interagissem cotidianamente com a experiência humana. Não obstante, seu esforço maior concentra-se em evidenciar os limites da própria capacidade científica em conhecer e transformar o ser humano.

Acima da etnologia e da psicanálise, mais exatamente intrincada com elas, uma terceira "contra-ciência" viria percorrer, animar, inquietar todo o campo constituído das ciências humanas e, extravasando-o, tanto do lado das positividades quanto da lado da finitude, formaria sua contestação mais geral. Como as duas outras contra-ciências, ela faria aparecer, num modo discursivo, as formas limites das ciências humanas; como elas, alojaria sua experiência nestas regiões iluminadas e perigosas onde o saber do homem trava, sob as espécies do inconsciente e da historicidade, sua relação com o que as torna possíveis. Todas as três põem em risco, expondo-o, aquilo mesmo que o possibilitou ser conhecido (FOUCAULT, 1999, p. 528). 


\section{Considerações finais}

A partir do exposto, todo o conhecimento científico pode ser objeto extensionista. A grande pergunta a responder é: atualmente, o que é e o que não é científico? Torna-se cada vez mais tênue se torna esta separação. Portanto, não encontraríamos mais positividade nos fenômenos de transformação prática, ou ainda, na práxis? Não seria através destes fenômenos que poder-se-ia observar com mais acurácia quando os discursos e construções científicas transformam e condicionam os diálogos?

O histórico da extensão demonstra que ela é derivada claramente de um processo de externalização social dos discursos e práticas científicas que, até dado momento, era passível de demarcação. Contudo, tal demarcação já não é tão visível atualmente. As sociedades especialistas de padrão moderno diluíram as fronteiras entre a ciência e as sociedades. Assim, este seria o principal ponto de problematização levantado por este ensaio, ou seja, de que os estudos em extensão já não podem ficar situados em uma dimensão etérea e imaginária, onde se destacam as comparações entre o ideal e o real. Os estudos em extensão estabelecem-se, atualmente, no âmbito do cotidiano social.

A trajetória epistemológica extensionista culmina na necessidade contemporânea de ressignificar as concepções intelectuais modernas, no sentido de reinterpretar seus aspectos ideais através dos filtros do cotidiano social. Alcançou-se o momento em que as aplicações ou proposições discursivas acadêmicas exigem inventários existenciais que preencham suas concepções. Nesse processo de ressignificação, os estudos em extensão deparam-se com uma necessidade pragmática, em sentido estrito. Na busca de determinar o significado ou de ressignificar um discurso ou uma concepção intelectual, "dever-se-ia considerar quais consequências práticas poderiam concebivelmente resultar, necessariamente, da verdade dessa concepção; e a soma destas consequências constituirá todo o significado da concepção" (PIERCE, 2012, p. 195). De modo geral, a aplicação ou a proposição discursiva acadêmica deveria pressupor, minimamente, um levantamento de suas consequências para, assim, recompor as matrizes conceituais do discurso extensionista. Caso contrário, seguir-se-ia tangenciando o risco de recair no fanatismo ideológico.

A atualização discursiva foi e continua sendo uma das mais marcantes características dos estudos em extensão. Sem embargo, é nesse processo que esses estudos conquistam sua genuinidade e, além disso, conquistam um espaço próprio na plataforma epistemológica moderna. Nesse caso, para arriscar-se atribuir uma denominação para o método epistemológico em extensão, a ser abordado em trabalhos futuros, poder-se-ia qualificá-lo preliminarmente como uma espécie de pragmatismo dialético ${ }^{6}$. Ou seja, uma abordagem que reflete sobre o universo das ideias derivadas, principalmente da atividade científica, em contexto de evidenciação do diálogo social para a transformação de suas dinâmicas existenciais. Em termos práticos, filosofia aplicada. Entretanto, tudo isso deverá transformar-se através das fronteiras da criatividade. Segue-se, portanto, com a des-coberta do fenômeno da episteme extensionista.

6 Ver maiores detalhes em Eemeren \& Grootendorst (2004). 


\section{REFERÊNCIAS}

ANDERSON, J. R.; FEDER, G. Rural Extension Services. The World Bank / Agriculture and Rural Development Department and Development Research Group Rural Development, Policy Research Working Paper 2976, Feb. 2003, 40p. Disponível em: http://wwwwds.worldbank.org/servlet/WDSContentServer/WDSP/IB/2003/03/22/00009494 6_03031111352821/Rendered/PDF/multiOpage.pdf. Acesso em: 01 fev. 2014.

BAUMAN, Z. Modernidade Líquida. Trad. Plínio Dentzien. Rio de Janeiro: Jorge Zahar Editor, 2001.

BOURDIEU, P. Razões Práticas. Papirus : Campinas, 2007.

Poder Simbólico. 10ª ed. Rio de Janeiro: Bertrand, Brasil, 2007.

BERGAMASCO, S. M. P. P. Agricultura e assistência técnica no Estado de São Paulo. Botucatu: FCA/UNESP, 1983. 286p. Tese (concurso de livre docência). F. C. A. do Campus de Botucatu, UNESP, 1983.

CAPORAL, F. R.; RAMOS, L. F. Da extensão rural convencional para à extensão rural para o desenvolvimento sustentável: enfrentar desafios para romper a inércia. BRASÍLIA, 2006.

CHAMBERS, R. Desenvolvimento Rural - Fazer dos últimos os primeiros. Edição ADRA. Luanda, Angola. 1995.

COCHRANE, W. W. Farm Prices, Myth and Reality. Minneapolis: University of Minnesota Press, 1958.

DÍAZ, E.; HELER, M. El Conocimiento Científico: hacia una visión crítica de la ciencia. Buenos Aires: Eudeba, 2000, Vol. II, p. 157-175.

. Introducción al conocimiento científico. Buenos Aires Eudeba, ediciones UBA XXI. 1997.

DIESEL, V.; FROEHLICH, J. M.; NEUMANN, P. S.; SILVEIRA, P. R. C. Privatização dos serviços de extensão rural: uma discussão (des)necessária?. Rev. Econ. Sociol. Rural [online]. 2008, vol.46, n.4, pp. 1155-1188.

EICHER, C. K. Agricultural extension in Africa and Asia. World AgInfo Project, Cornell University, Ithaca, New York. Aug. 15, 2007, 24p. Disponível em: <http://worldaginfo.org/drupal/files/Agricultural\% 20Extension\% 20in\% 20Africa \%20and\% 20Asia2.pdf>. Acesso em: 05 fev. 2014.

EEMEREN, F.H.V.; GROOTENDORST, R. A systematic theory of argumentation: The pragma-dialectical approach. Cambridge: Cambridge University Press, 2004.

ESCOBAR, A. Una minga para el postdesarrollo: lugar, medio ambiente y 
movimientos sociales en las transformaciones globales. Programa Democracia y Transformación Global, Lima, 2010.

FEDER, G.; WILLETT, A.; ZIJP, W. Agricultural Extension: Generic Challenges and Some Ingredients for Solutions. World Bank Policy Research Working Paper No. 2129, May 1, 1999, 33p. Disponível em: <http://www.worldbank.org/html/dec/Publications/Workpapers/wps2000series/ wps2129/wps2129.pdf>. Acesso em: 05 fev. 2014.

FIGUEIREDO, R. P. de Extensão rural no Brasil: novos tempos. Brasília, Rev. Bras. Tec, v.15 (4), jul/ago, 1984.

FONSECA, M. T. L. A extensão rural no Brasil, um projeto educativo para o capital. São Paulo: Ed. Loyola (Série Educação popular v.3), 1985.

FOUCAULT, M. As palavras e as coisas: uma arqueologia das ciências humanas. Trad. Salma Tannus Muchail. 8ª Edição. São Paulo: Martins Fontes, 1999.

FREIRE, P. Extensão ou comunicação. 13ª edição, São Paulo: Paz e Terra, 2006.

FREITAS NETO, J. A. (2011). A reforma universitária de Córdoba (1918): um manifesto por uma universidade latino-americana. Ensino Superior Unicamp, 3, $62-73$.

GOFFMAN, E. A representação do Eu na vida cotidiana. Vozes : Petrópolis, 2002. . Manicômios, prisões e conventos. São Paulo : Perspectiva, 2005.

HARVEY, D. A condição pós-moderna: uma pesquisa sobre as origens da mudança cultural. São Paulo: Edições Loyola, 1999.

HEIDEGGER, M. Ser e tempo. 7ª ed. Petropolis, Vozes, 1998.

KUHN, T. A estrutura das revoluções científicas. São Paulo: Perspectiva, 1992.

LIMA, I. A. A extensão rural e a produção do conhecimento: a fundamentação científica dos planos municipais de desenvolvimento rural do programa nacional de fortalecimento da agricultura familiar (Pronaf) no Estado de São Paulo. Dissertação (Mestrado em Engenharia Agrícola). Universidade Estadual de Campinas, Campinas, 2001.

MALDONADO, T. Meio ambiente e ideologia. Lisboa: Sociocultur, 1971.

MAZOYER, M.; ROUDART, L. História das agriculturas no mundo: do neolítico à crise contemporânea. Tradução de Cláudia F. Falluh Balduino Ferreira. São Paulo: Editora UNESP; Brasília, DF: NEAD, 2010.

MORAES, C. S. A trajetória da comunidade científica do programa de pós- 
graduação em extensão rural e a emergência de novo paradigma para a extensão rural. Tese (Doutorado em Extensão Rural). Programa de Pós-Graduação em Extensão Rural da Universidade Federal de Santa Maria, Santa Maria, 2013.

PEIRCE, C. S. Semiótica; [tradução José Teixeira Coelho Neto]. São Paulo: Perspectiva, 2012.

PEIXOTO, M. Extensão Rural no Brasil - uma abordagem histórica da legislação. Textos para discussão 48. Senado Federal: Brasília, 2008. Disponível em: http://www.senado.gov.br/conleg/textos_discussao.htm. Acesso em: $05 \mathrm{fev}$. 2014.

A Extensão Privada e a Privatização da Extensão: uma Análise da Indústria de Defensivos Agrícolas. Tese (Doutorado em Ciências Sociais). Programa de Pósgraduação de Ciências Sociais em Desenvolvimento, Agricultura e Sociedade da Universidade Federal Rural do Rio de Janeiro, Seropédica, 2009. Disponível em: http://www.senado.gov.br/conleg/textos_discussao/TESEMarcusPeixoto.pdf.

Acesso em: 05 fev. 2014.

RIVERA, W. M.; ALEX, G. (editors). Demand-Driven Approaches to Agriculture Extension - Case Studies of International Initiatives. Washington: World Bank. Agriculture and Rural Development Discussion, Paper 10 (Extension Reform for Rural Development Volume 3), 2004, 123p. Disponível em: <http://Inweb18.worldbank.org/ESSD/ardext.nsf/11ByDocName/ExtensionRefor mforRuralDevelopmentVolume3DemandDrivenApproachestoAgricultureExtension/ \$FILE/Extension_Reform_V3_final.pdf>. Acesso em: 05 fev. 2014.

ROCHA, R. M. G. A construção do Conceito de Extensão Universitária na América Latina. In: Construção do Conceito da Extensão Universitária na América Latina. Brasília: Universidade de Brasília, 2001.

RODRIGUES, C. M. Conceito de Seletividade de Políticas Públicas e sua Aplicação no Contexto da Política de Extensão Rural no Brasil. In: Cadernos de Ciência \& Tecnologia, Brasília, v. 14, n. 1, p. 113-154, 1997.

ROGERS, E. M. Diffusion of Innovations. 5 ed. New York: Free Press, 2003.

RÖLING, N. La comunicación para el desarrollo en la investigación, la extensión y la educación. Comunicación y Desarrollo Sostenible: Selección de artículos de la 9a mesa redonda de las Naciones Unidas sobre comunicación para el desarrollo. FAO/ONU. Roma, 2007. p. 65-90.

RYAN, B.; GROSS, N. C. The diffusion of hybrid seed corn in two lowa communities. Rural Sociology, v. 8, n. 1, p. 15-24, 1943.

SABOURIN, E. Teoria da Reciprocidade e sócio-antropologia do desenvolvimento. Sociologias, Porto Alegre, ano 13, n²7, mai./ago. 2011, p. 24-51. 
SAMPAIO, O. B. Contextualização Histórica da Extensão e Seus Reflexos na Sociedade Brasileira. In: III Encontro de Extensão da Universidade Federal de Campina Grande. Campina Grande, 2004.

SOUSA SANTOS, B. Um Discurso sobre as Ciências. Edições Afrontamento, Porto, 1988.

UNITED STATES OF AMERICA. Smith-Lever Act As Amended Through Public Law. 107-293, Nov. 13, $2002 . \quad$ Disponível em: http://www.csrees.usda.gov/about/offices/legis/pdfs/smithlev.pdf . Acesso em: 05 fev. 2014.

WEBER, M. Metodologia das Ciências Sociais - parte II. São Paulo, Cortez, 2001. El político y el científico. Madrid, Alianza Editorial, 1975. A ética protestante e o "espírito" do capitalismo. São Paulo, Companhia da Letras, 2004.

Submetido em 08/01/2015

Aprovado em 12/08/2016

\section{Silvio Calgaro Neto}

Doutorando do Programa de Pós-Graduação em Extensão Rural da Universidade Federal de Santa Maria e do Programa de Doutorado em Ciências Econômicas, Empresariais e Sociais da Universidad de Sevilla.

E-mail: silviocalgaro@gmail.com

\section{Renato Santos de Souza}

Professor adjunto do Departamento de Educação Agrícola e Extensão Rural e do Programa de PósGraduação em Extensão Rural da Universidade Federal de Santa Maria.

E-mail: renatosdesouza@gmail.com 